\title{
Undergraduate Student Feedback on OSCE: The First Experience of a Nutrition Department, University of Benghazi 2019
}

\author{
Salima Elfagi", Souad F. Elamni, Faiza Nouh, Ashmisa Eltohami, Mariam Omar
}

Department of Nutrition, Faculty of Public Health, Benghazi University, Benghazi, Libya

\author{
DOI: $10.36348 /$ jaep.2020.v04i05.001 $\quad$ | Received: 23.04 .2020 | Accepted: 30.04 .2020 | Published: 07.05 .2020 \\ *Corresponding author: Salima Elfagi
}

\section{Abstract}

The Objective Structured Clinical Examination (OSCE) is becoming more widespread within healthcare education programmers, because it is considered as a suitable method for assessing skills and underpinning knowledge essential for practice $^{1}$. The OSCE is also an assessment method in which students establish their competence under a multiple of simulated conditions. In addition, the OSCE is a very different experience for the students, in contrast to more traditional methods of assessment such as written assignments, writing essay, multiple choices and continuous assessment in practice. The aim of this study was to assess the third year nutrition student's perception about the Objective Structured Clinical Examination (OSCE) in the clinical nutrition practice. Study was conducted in Al-Gala Hospital and Medical Benghazi Center on undergraduate students around 120 students was included in this exam. $74 \%$ of the students indicated that they were received adequate information about exam before conducting it, and about $72 \%$ reported that the instructions of each station were as expected. $50 \%$ of students found OSCE exam was easy than essay question, oral and MCQ exam, while the most average exam was oral exam as reported by $54 \%$ of students and $35 \%$ of them found that MCQ exam was more fair exam than OSCE and other exams. Shows that the most factors that facing student during conducting OSCE exam were stressful and time that conducted at each station, $78 \%$ of students said the exam was so stressful and $69 \%$ of them reported the time was not enough at each station. This study concluded that the structure and design OSCE exam were clear and organized and most of students received adequate information before conducting the exam. Almost of students agreed with the OSCE exam is the useful experience to improve their practical skills in clinical nutrition.

Keywords: Undergraduate Student, Feedback on OSCE, First Experience, Nutrition students, Dietitians.

Copyright @ 2020: This is an open-access article distributed under the terms of the Creative Commons Attribution license which permits unrestricted use, distribution, and reproduction in any medium for non-commercial use (NonCommercial, or CC-BY-NC) provided the original author and sources are credited.

\section{INTRODUCTION}

The Accreditation Council for Education in Nutrition and Dietetics (ACEND) in 2013 [1, 2] which sets the approval standards to ensure quality and continued improvement of the nutrition and dietetics education programs worldwide, recommends the use of multiple educational approaches, including role-play, problem-based learning, and simulation which may allow improve clinical education skills among the students [3].

Practical education involves assessment of students at fixed intervals as a source of learning and offering the basis for improving the competence level. In this context, skill based assessments are importance in addition to information based tests.

These manners of assessment include the Objective Structured Clinical Evaluation (OSCE). This tool has been used for assessment of skills in the basic of nutrition care processes during the third and fourth year, and clinical years of a nutrition curriculum [4]. OSCE is an assessment tool in which the sections of clinical competence such as general history taking, food and nutrition history, nutrition focused physical examination, interpretation of laboratory results, and patient intervention and management are assessed. Furthermore, the communication and opinion skills are assessed. Through out assessment, the student rounded a number of stations, some of which have observers with check lists of behaviors the students should exhibition [5].

Different studies have showed that OSCE is a reliable tool that has a good capability to differentiate between clinical skills of different students $[5,6]$. 
It is progressively hard to offer adequate clinical training for undergraduate students. Internships are difficult to obtain and often present defies to overloaded clinicians.

Providing better-prepared and more confident undergraduates may help to make the shift from academic to real-life practice easier and less worrying [7]. Nutritionist students obtain clinical experience during their academic program largely through visiting patients and observing patient charts in hospital settings. Problems that predictably occur with this model include lack of nutritional physical examination, inconsistencies in opportunities for counseling, gaps between malnutrition prevalence and diagnosis, and vast differences in the level of supervision and the quality of clinicalinstruction [8].

To deal with these problems, the Objective Standardized Clinical Examination (OSCE), which in 2002 was designated as the "gold standard for clinical assessment" and in 2004 became part of the United States Medical Licensing Examination (USMLEstep II). OSCEs are currently used in more than 50 countries worldwide and in numerous disciplines, including nutritionand dietetics [9].

The significance of student's feedback regarding the assessment tools in undergraduate nutrition education has been increasingly recognized, and students' feedback on their curriculum has been measured as an effective method toward more active teaching [10]. Students' feedback is considered as a key pointer for successful application of OSCE and also provides an instinct for improvement. Therefore, this study aimed to evaluate undergraduate students' feedback regarding OSCE exam and to compare student's grades in these OSCE exams with their feedback.

\section{Aim of the Study \\ The aim of this study was to assess the third year nutrition student's perception about the Objective Structured Clinical Examination (OSCE) in the clinical nutrition practice.}

\section{METHODOLOGY}

\section{Setting}

Study was conducted in Al-Gala Hospital and Medical Benghazi Center on undergraduate students in Nutrition department, faculty of Public Health, University of Benghazi. The students enrolled for the first time in the OSCE final exam during the academic year 2018-2019.

\section{Participants}

The study involved all third year (pregraduated year) nutrition students $(n=120)$, they were 3 males and 117 female with mean age 24 years. The students enrolled in six stations include general nutritional assessment block, diet plane block, anthropometric and interpretations block, during the 2018-2019 academic year.

\section{Study Design}

The study was conducted during the doing of OSCE exam. OSCE was designed as 7 stations at which the students will rotate and make a stop for 2-5 minutes on each station. These stations were distributed according to different disciplines included in the clinical nutrition practical course. The number of stations per discipline varied and included the following, history station for 5 minute; nutrition care processes for 10 minute, anthropometric station for 3 minute, case discussion station for 10 minute, photo station for 2 minute and finally chart interpretation station for 2 minute. The OSCE exam began with a 15minute orientation, which defined the process, movement from station to station, and how students should perceive their role as a professional dietitian.

\section{Data Collection}

All students were informed about the aim of the study, and its significance. They were invited to provide their feedback about OSCE as an assessment tool for their practical skills. All students were assured that the study would be managed secretly to protect their confidentiality.

The feedback Questionnaires related to OSCE were distributed to all students to obtain their views and comments, and they were collected before they left the session of the exam. Feedback Questionnaire was validated by senior experts and it contained 20 questions that include questions about design of OSCE exam, factors affected the exam, students' views about the instruction during conducting exam, and their opinion about exam as assessment tool to improve their clinical skills.

\section{Statistical Analysis}

The Statistical Package for the Social Science version 16.0 (SPSS) program was used to analysis the data. Descriptive statistical tests were conducted to make comparison including frequency and percentage. Chi square was used to investigate the presence any differences between variables.

\section{Ethical Approval}

An ethical approval was obtained from Dean of faculty of Public Health and Head of Nutrition Department, University of Benghazi.

\section{RESULTS}

Structure and design of OSCE exam were clear and organized. Around $80 \%$ of students indicated that OSCE exam was designed fairly and organized properly and about $78 \%$ of them reported the exam covers a wide area of knowledge about nutrition practice (See Table-1). 
Salima Elfagi et al; J Adv Educ Philos, May, 2020; 4(5): 187-191

Table-1: Opinions of the students about structure and design of OSCE

\begin{tabular}{|l|l|l|l|}
\hline Variable & Agreement & $\mathbf{N}$ & $\%$ \\
\hline Exam designed fairly & Agree & 91 & 79 \\
& Disagree & 24 & 21 \\
\hline Exam organized properly & Agree & 91 & 79 \\
& Disagree & 24 & 24 \\
\hline Exam covered a wide area of & Agree & 90 & 78 \\
knowledge & Disagree & 25 & 22 \\
\hline
\end{tabular}

In regarding the instruction of OSCE exam, most of students (74\%) indicated that they were received adequate information about exam before conducting it, and about $72 \%$ of students reported that the instructions of each station were as expected. More than half of student mentioned that the instructions of exam were clear and unambiguous and the time of exam was enough for each station, 67\%, 59\% respectively (See table-2).
Table-2: Views of students about the instruction and conducting of OSCE exam

\begin{tabular}{|l|l|l|l|}
\hline & & N & \% \\
\hline $\begin{array}{l}\text { Received adequate } \\
\text { information before } \\
\text { appearing in the exam }\end{array}$ & Yes & 82 & 74 \\
No & 29 & 26 \\
$\begin{array}{l}\text { The instruction of each } \\
\text { station were as }\end{array}$ & Yes & 84 & 72 \\
expected & No & 32 & 28 \\
\hline $\begin{array}{l}\text { Instructions were clear } \\
\text { and unambiguous }\end{array}$ & Yes & 76 & 67 \\
\hline $\begin{array}{l}\text { The time was enough } \\
\text { for each station: }\end{array}$ & Yes & 37 & 33 \\
\hline
\end{tabular}

Figure-1 shows that the most factors that facing student during conducting OSCE exam were stressful and time that conducted at each station, $78 \%$ of students said the exam was so stressful and $69 \%$ of them reported the time was not enough at each station.

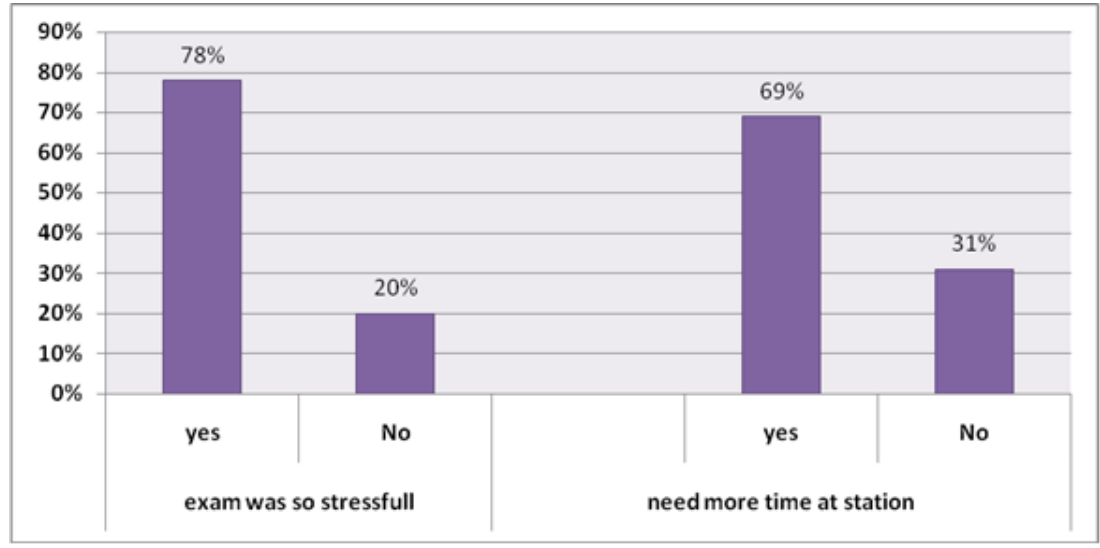

Fig-1: Factors affected conducting of OSCE exam as reported by students

The Opinions of students about their experience of OSCE exam were good. The majority of students were agree with OSCE exam is practical and useful experience, OSCE scores provide true measure of essential clinical skills of undergraduate nutrition students, and OSCE scores are standardized, 87\%, 86\% and $83 \%$ respectively. More than half of participants $(67 \%)$ reported that exam minimized chance of failing, and $52 \%$ of them agreed with the examiner personality and social relations will not affect OSCE scores (See Table-3).

Table-3: Distribution percentage of student's opinion regarding experience of objective structured clinical examination

\begin{tabular}{|l|l|l|l|}
\hline Evaluation of Experience & Agreement & $\mathbf{N}$ & $\mathbf{\%}$ \\
\hline Performing of tasks at each station was interesting and educative: & Agree & 89 & 76 \\
& Disagree & 27 & 23 \\
\hline Exam minimized chance of failing: & Agree & 77 & 67 \\
& Disagree & 38 & 33 \\
\hline Examiner personality and social relations will not affect OSCE scores & Agree & 60 & 52 \\
& Disagree & 55 & 48 \\
\hline OSCE scores are standardized & Agree & 95 & 83 \\
& Disagree & 20 & 17 \\
\hline OSCE practical and useful experience & Agree & 91 & 87 \\
& Disagree & 15 & 13 \\
\hline OSCE scores provide true measure of essential clinical skills & Agree & 100 & 86 \\
& Disagree & 16 & 14 \\
\hline
\end{tabular}


When comparing OSCE exam with other types of exam, $50 \%$ of students found OSCE exam was easy than essay question, oral and MCQ exam, while the most average exam was oral exam as reported by $54 \%$ of students and $35 \%$ of them found that MCQ exam was more fair exam than OSCE and other exams (See Figure-2).

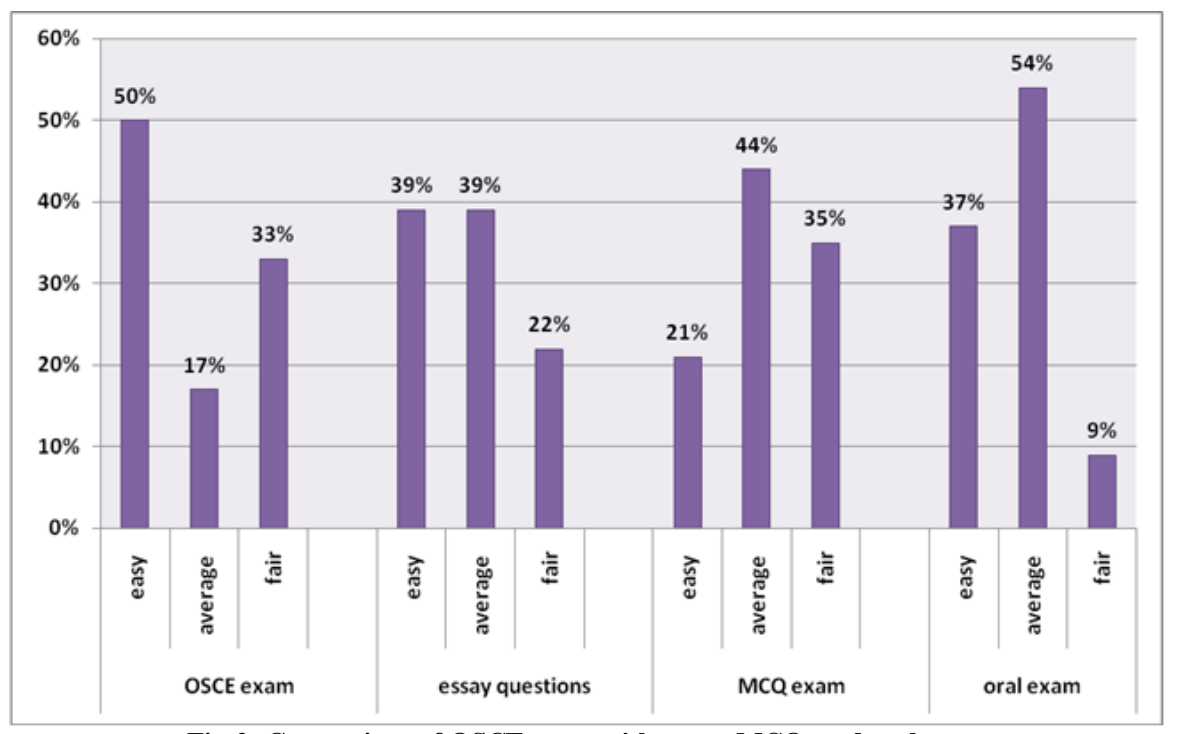

Fig-2: Comparison of OSCE exam with essay, MCQ, and oral exam

\section{DISCUSSION}

Objective Structured Clinical Examination is considered by some what a golden standard for assessing clinical skills. It appears to be important for performance discrimination on the basis of individual competency, and attitude towards learning [12]. It may not only improve the quality of students' performance in the result but may also prepare them for their clinical years so that good nutritionist may be produced. OSCE is a new evaluation experience for the nutrition department faculty of public health, Benghazi University, which was applied in the department in 2019 of academic year.

In our study the feedback from nutrition students suggests that OSCE is an actual tool for evaluating clinical skills. Students seeming OSCE scores as a true measure for the essential clinical skills being evaluated, standardized, and not disturbed by the student's and examiner personality or social relations, (83\%, 53\% respectively). Similar results were reported by Winnie Chee 2018 [13], about $70 \%$ of dietitian students felt the OSCE was an objective measure of clinical skills attainment and had a positive experience in the OSCE. In confirm to the results of the current study another study was conducted in Sudan to evaluating student's OSCE experience that found most of students were agree with OSCE exam is clear and the personality didn't affect its conducting [14]. The majority of students enjoyed this experience and indicated the OSCE exam was designed fairly and properly because it was much more realistic than simply asking patients a list of questions at the medical center. Similar results done in Sudan revealed that $92 \%$ of the nutrition students found OSCE to be a flexible and realistic experience [3].

Most students provided positive feedback aboutthe evaluation of quality of OSCEC performancein terms of the clarity of the instructions on the exam, the sequence of OSCE stations, the reflection of the tasks taught and the time at each station and they received enough knowledge before the exam day. These results are supported by Pierre et al., findings [15].

Nevertheless, the OSCE was apparent as a stressful experience, frightening and the time was not enough by a considerable percentage of students, even though they prepared well before the exam as study percentage. This opinion could be due to the fact that the OSCE exam is a new experience was applied on students and could be they faced difficult to deal with this type of assessment. In future it would be preferable to use the OSCE in third year as a training step for students before the final OSCE. These findings are similar to another studies were conducted Malaysia 12 which indicated that the majority of students still graded this method of assessment as stressful and anxious experience [12, 16]. However, Byrne and Smyth $2008{ }^{16}$ concluded that students already exposed to an OSCE described feeling less anxious, better prepared for their subsequent clinical placements .In regarding to the time as factor affected the exam Chee 2018 indicated that the majority of dietitian students agreed that 10 minutes were adequate for most stations [13]. Flexibility of the time in each station is needed to reduce the stress among the students during conduction the exam. 
On the other hand OSCE was compared with other forms of assessment as essay exam, multiple choice question exams and oral exam; the results showed that, OSCE is an easy and acceptable alternative to traditional means of examination in nutrition. Similar data was reported by Jafarzadeh [17] also showed that the OSCE was easy as seen by majority $(85.7 \%)$ of students compare to MCQ and oral exam. This is likely to be explained by the fact that Students had no face to face encounter with examiner during OSCE which helped the students to be, more confident.

\section{CONCLUSION}

This study concluded that the structure and design OSCE exam were clear and organized and most of students received adequate information before conducting the exam. Almost of students agreed with the OSCE exam is the useful experience to improve their practical skills in clinical nutrition. The current study recommended that the OSCE exam is important method of assessment should be conducted in practical academic year of the study.

\section{REFERENCES}

1. Watson, R., Stimpson, A., Topping, A., \& Porock, D. (2002). Clinical competence assessment in nursing: a systematic review of the literature. Journal of advanced nursing,39(5), 421-431.

2. Merriman, C., \& Westcott, L. (2010). Succeed in osces and practical exams: an essential guide for nurses: an essential guide for nurses. McGrawHill Education (UK).

3. Farahat, E., Rice, G., Daher, N., Heine, N., Schneider, L., \& Connell, B. (2015). Objective Structured Clinical Examination (OSCE) improves perceived readiness for clinical placement in nutrition and dietetic students. Journal of allied health, 44(4), 208-214.

4. ACEND. Availability of Dietetic Internship Positions.hicago: Accreditation Council for Education in Nutrition and Dietetics. Available at: http://www.eatright.org/ACEND/content.aspx? id=4294967919. Accessed Aug 12, 201.

5. Shankar, P. R., Gurung, S. B., Jha, N., Bajracharya, O., Ansari, S. R., \& Thapa, H. S. (2011). Practical Assessment in Pharmacology at A New Nepalese Medical School. Journal of Clinical and Diagnostic Research 4:3314-3316

6. Harden, R. M., Stevenson, M., Wilson, D. W, Wilson, G. M. (1975). Assessment of clinical competencies using objective structured clinical examination. BMJ. 5955(1): 447-51.

7. Tooth, D., Tonge, K., \& McManus, I. C. (1989). Anxiety and study methods in preclinical students: causal relation to examination performance. Medical education, 23(5), 416-421.

8. Nayar, U., Malik, S. L., \& Bijlani, R. L. (1986). Objective structured practical examination: a new concept in assessment of laboratory exercises in preclinical education, 20(3):204-209. sciences. Medical

9. Torres, S., Winter, J., Matters, H., \& Nowson, C. (2002). Direct patient contacts of dietetic students during their final clinical placement. Nutrition \& dietetics, 59(1), 18-22.

10. Barrows, H. S. (1993). An overview of the uses of standardized patients for teaching and evaluating clinical skills. Academic Medicine-Philadelphia, 68, 443-443.

11. Patrício, M. F., Julião, M., Fareleira, F., \& Carneiro, A. V. (2013). Is the OSCE a feasible tool to assess competencies in undergraduate medical education?. Medical teacher, 35(6), 503 514.

12. Nouh, F., Elfagi, S., \& Omar, M. (2020). Influence of Integrated Teaching Strategies on Quality of Student Outcomes in A Clinical Nutrition Course in Undergraduate Level at Nutrition Department Faculty of Public Health; University of Benghazi. Journal of Advances in Education and Philosophy, 4(2):1-4.

13. Russell, M. L., Caggiula, A. W., \& Gloninger, M. F. (1985). Evaluation of clinical skills for nutrition counseling. Journal of the American College of Nutrition, 4(5), 521-529.

14. Winnie, C., \& Esther, M. (2018). Teaching and evaluating critical thinking in dietetics using NCP/T: OSCE'S, KAHOOTS AND SOCRATIVE. International Affiliated of the Academy of Nutrition and Dietetics.

15. Fidment, S. (2012). The objective structured clinical exam (OSCE): A qualitative study exploring the healthcare student's experience. Student engagement and experience journal, 1(1), 1-18.

16. Eswi, A., Samy, A., \&Shaliabe, H. (2013). OSCE in maternity and community health nursing: Saudi nursing student's perspective. American Journal of Research Communication, 1(3), 143-62.

17. Byrne, E., \& Smyth, S. (2008). Lecturers' experiences and perspectives of using an objective structured clinical examination. Nurse Education in Practice, 8(4), 283-289. 